\title{
SiC Fiber/Borosilicate Glass Composite (Part 3) \\ Thermal-Shock Behaviour-
}

\author{
Dong-Woo SHIN, Keun Ho AUH and Kevin M. KNOWLES*
}

Ceramic Materials Research Institute, Hanyang University, Seoul 133-791, Korea

*Department of Materials Science and Metallurgy, University of Cambridge, Pembroke Street, Cambridge CB2 3QZ, United Kingdom

\section{$\mathrm{SiC}$ 繊維/ホウケイ酸ガラス複合材（第 3 報） 一熱衝撃挙動}

\author{
Dong-Woo Shin · Keun Ho Auh • Kevin M. Knowles*
}

Ceramic Materials Research Institute, Hanyang University, Seoul 133-791, Korea

*Department of Materials Science and Metallurgy, University of Cambridge, Pembroke Street, Cambridge CB2 3QZ, United Kingdom

[Received July 18, 1994; Accepted January 19, 1995]

\begin{abstract}
The influence of thermal stresses on the mechanical properties of thermal-shocked Nicalon SiC fibre/Pyrex composites has been analysed by considering the effect of thermal-mismatch stress on the mechanical properties of composite constituents. The thermal-mismatch stresses developed between devitrified cristobalite, and fibre and glass matrix were calculated using the values of material parameters obtained from experiment. This shows that the high thermal mismatch stresses originating from larger coefficient of thermal expansion of devitrified cristobalite extended the preexisting matrix crack, and caused fibre debonding. Thus, the reductions in the modulus and the interfacial stress of thermal-shocked composites in comparison with those of as-fabricated composites resulted from the matrix devitrification. The lower proportional limit of thermal-shocked composite was attributed to the lower interfacial stress and larger pre-existing cracks compared with those of as-fabricated composite. The reduction in ultimate strength of thermalshocked composite was correlated with the decreases of fiber hardness and interfacial stress.
\end{abstract}

Key-words : SiC fibre/Pyrex composite, Thermal-shock treatment, Mechanical properties, Thermal stress

\section{Introduction}

Successfully developed fibre-reinforced ceramic matrix composites (FRCMCs) have shown a high work-of-fracture $\left(\approx 70 \mathrm{~kJ} / \mathrm{m}^{2}\right)$ and a high Weibull modulus $(\approx 30)$ and therefore less sensitivity of their mechanical properties to matrix flaws in comparison with monolithic ceramics. ${ }^{1)}$,2) However, few studies on the influence of thermal stress on the firstmatrix cracking stress and the ultimate strength of composites have been made for glass and glass-ceramics matrix fibre composites, ${ }^{3), 4)}$ although in service FRCMCs will be subjected to conditions of high heat transfer and rapid environmental temperature variations.

The effect of thermal mismatch on the interfacial stress and pre-stresses developed in the matrix, and their effects on the first-matrix cracking stress $\sigma_{\mathrm{cr}}$ have been described by Budiansky et al. ${ }^{5}$ The influence of a residual axial stress $\sigma_{\mathrm{m}}^{\mathrm{I}}$ in the matrix on the matrix failure strain $\varepsilon_{\mathrm{mu}}$ is given by,

$$
\varepsilon_{\mathrm{mu}}=\left\{\frac{12 \tau \gamma_{\mathrm{m}} E_{\mathrm{f}} V_{\mathrm{f}}^{2}}{E_{\mathrm{c}} E_{\mathrm{m}}{ }^{2} r V_{\mathrm{m}}}\right\}^{1 / 3}-\frac{\sigma_{\mathrm{m}}^{\mathrm{I}}}{E_{\mathrm{m}}}
$$

where $E_{\mathrm{f}}$ and $E_{\mathrm{m}}$ are the Young's moduli of the fibre and matrix and $V_{\mathrm{f}}$ and $V_{\mathrm{m}}$ are the volume fractions of fibre and matrix $\left(V_{\mathrm{f}}+V_{\mathrm{m}}=1\right)$, and $\tau$ is the frictional stress of interface, $2 \gamma_{\mathrm{m}}$ the fracture surface energy of the matrix, and $r$ is the fibre radius, and $\sigma_{\mathrm{m}}^{\mathrm{I}}>0$, if there is a residual tensile stress and $\sigma_{\mathrm{m}}^{\mathrm{I}}<0$ for compressive stress.

In addition, the thermal mismatch between fibre and matrix will produce a pressure $P$ at the fibre/ matrix interface. Assuming that the interfacial friction stress $\tau$ is determined by a Coulomb friction law, the friction stress at interface has the form

$$
\tau=\mu P
$$

where $\mu$ is the coefficient of friction. $\sigma_{\mathrm{m}}^{\mathrm{I}}$ in Eq. (1) and $P$ in Eq. (2) can be calculated using an isolated composite-cylinder shear-lag model. ${ }^{5}$ )

The resultant expressions for the axial stress in the matrix and the pressure acting on the interface in terms of material parameters are,

$$
\begin{aligned}
& \frac{P}{E_{\mathrm{m}}}=\frac{1}{2 \lambda_{1}}\left\{\frac{V_{\mathrm{m}}}{1-v_{\mathrm{m}}}\right\} \Omega \\
& \frac{\sigma_{\mathrm{m}}^{\mathrm{I}}}{E_{\mathrm{m}}}=\frac{\lambda_{2}}{\lambda_{1}}\left(\frac{E_{\mathrm{f}}}{E_{\mathrm{c}}}\right)\left\{\frac{V_{\mathrm{f}}}{1-v_{\mathrm{m}}}\right\} \Omega
\end{aligned}
$$

where $v_{\mathrm{m}}$ is the Poisson's ratio of matrix, and $\Omega$ is the strain mismatch defined by $\left(\alpha_{\mathrm{m}}-\alpha_{\mathrm{f}}\right) \Delta T$ when the mismatch is only due to thermal strain. If $v_{\mathrm{m}}=v_{\mathrm{f}}=v$, $\lambda_{1}$ and $\lambda_{2}$ are given by,

$$
\begin{aligned}
& \lambda_{1}=1-\frac{1}{2}\left(\frac{1-2 v_{\mathrm{m}}}{1-v_{\mathrm{m}}}\right)\left(1-\frac{E_{\mathrm{c}}}{E_{\mathrm{f}}}\right) \\
& \lambda_{2}=\frac{1}{2}\left(1+\frac{E_{\mathrm{c}}}{E_{\mathrm{f}}}\right)
\end{aligned}
$$


In FRCMCs, the failure-strain of the fibre $\varepsilon_{\mathrm{fu}}$ is generally greater than that of matrix $\varepsilon_{\mathrm{mu}}$. If $\alpha_{\mathrm{m}}>\alpha_{\mathrm{f}}$, the residual axial tensile stress developed resulting from thermal mismatch in the matrix causes a reduction of $\varepsilon_{\mathrm{mu}}$ when the composite is stressed parallel to the fibre axis. However, the effect of thermal stresses on first-matrix cracking stress predicted by the fracture mechanic approach has not been clearly established experimentally.

The aim of this study is to show how the thermal stresses developed both between the devitrified crystals and glass matrix, and between the fibre and the matrix can influence the mechanical properties of microcracked composites. In doing this, both the mechanical properties of composite and properties of composite constituents obtained from thermalshocked SiC fibre/Pyrex composites are compared with those of as-received composites. This will show how the thermal stresses can influence the properties of composite constituents, and also show how the changes of these properties can affect the ultimate strength, the proportional limit and the modulus of thermal-shocked composites.

\section{Experimental procedure}

Composites consisting of $\approx 50 \mathrm{vol} \%$ uniaxially aligned Nicalon fibre and Pyrex matrix have been used for this study. Each of as-received composite tile having dimensions of $98 \mathrm{~mm}$ in length, $30 \mathrm{~mm}$ in width, and $0.4-0.62 \mathrm{~mm}$ in thickness were cut into 8 flexural specimens. Half specimens obtained from each tile were tested in as-fabricated state, and remaining 4 samples were used for this study. Thus, the composites examined in this work have identical fabrication conditions, dimension and span to depth ratio for three-point flexural test as those mentioned for the corresponding as-fabricated samples. ${ }^{6)}$ With exception of 1-A specimen which was the Tyranno fibre composites and failed in a brittle manner, all the other specimens in the first set of earlier work ${ }^{6)}$ were thermal shock treated for this study. Thus, the notation of specimen used in this work, i.e., B, C and $\mathrm{D}$, indicates the identical $1-\mathrm{B}, 1-\mathrm{C}$ and $1-\mathrm{D}$ specimens in the earlier work, respectively. Four samples from each tile were heated slowly with heating rate of $\sim 10^{\circ} \mathrm{C} / \mathrm{min}$ up to $500^{\circ} \mathrm{C}$ and held for $10 \mathrm{~min}$ in air, and then quenched in a water bath of $20^{\circ} \mathrm{C}$ to investigate the effect of thermal-shock. The temperature of $500^{\circ} \mathrm{C}$ was chosen as being representative of an upper limit to the temperature regime that these composites could expect to meet in realistic service condi-tions.

Measurements of the three-point flexural strength, proportional limit, elastic modulus of composite, work-of-fracture, interfacial shear stress and fibre hardness of the thermal-shock treated samples were performed using the same methods applied to the asfabricated samples, as described in elsewhere. ${ }^{6)} \mathrm{A}$ powder diffraction method with calibration mixtures for external standards were also used to determine the amount of cristobalite phase in the thermalshocked samples. Each dimension for the calculation of interfacial stress and fibre hardness was determined by optical micrographs. For the measurement of fibre hardness, a $30 \mathrm{~g}$ load was applied to the top surface of the sample coated with $\sim 30 \mathrm{~nm}$ thick gold. Transverse and longitudinal sections polished using identical conditions from as-fabricated and thermal shock treated specimens were examined in the back-scattered electron mode of a scanning electron microscopy (SEM) at $35 \mathrm{kV}$ to distinguish fibres from the matrix, and to show matrix microcracks.

\section{Results and discussion}

\subsection{Mechanical properties of thermal-shocked composites}

The stress-deflection curves shown in Fig. 1 show a reduction of ultimate strength, proportional limit and elastic modulus of composite after the thermalshock treatment. All the thermal-shocked composites were failed with an extensive fibre pull-out, as we could predict from an initial elastic behaviour followed by an extended regime of increasing load-bearing capacity in the stress-deflection curve.

Comparison of the mechanical properties of thermal-shock treated samples with those of as-fabricated composites are shown in Table 1. The apparent interfacial stresses of thermal-shocked specimens measured by the indentation methods reduce to about one third of the values of as-fabricated samples, and the elastic of thermal-shocked composites also show reduced values of $\sim 95 \mathrm{GPa}$ compared with $\sim 100 \mathrm{GPa}$ of as-fabricated samples. However, it is worth noting that within the thermal-shocked samples, all composites exhibited approximately equal values of interfacial stress $(\sim 15 \mathrm{MPa})$, and showed roughly constant magnitudes of the proportional limits of $\sim 460 \mathrm{MPa}$ and ultimate strengths of $\sim 760 \mathrm{MPa}$. The amount of cristobalite in the thermally shocked samples was the same as in the as-

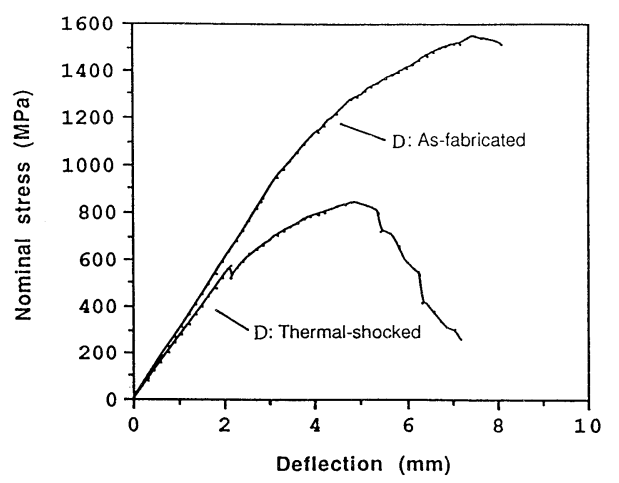

Fig. 1. Stress-deflection behaviours of as-fabricated and thermal-shock treated sample D in Table 1 obtained from flexural tests showing the reductions of the ultimate strength, the firstmatrix cracking stress and the elastic modulus after thermalshock treatment. 
Table 1. Comparison of the Mechanical Properties of the Thermal-Shock Treated Samples with Those of As-Fabricated SiC/Pyrex Composites ${ }^{1)}$

\begin{tabular}{|c|c|c|c|c|c|c|c|c|}
\hline & Specimens ${ }^{(2)}$ & $\begin{array}{l}\text { Ultimate } \\
\text { Strength } \\
\text { (MPa) }\end{array}$ & $\begin{array}{l}\text { Proportional } \\
\text { Limit } \\
(\mathrm{MPa})\end{array}$ & $\begin{array}{c}\text { Elastic } \\
\text { Modulus } \\
\text { of Composite } \\
(\mathrm{GPa})\end{array}$ & $\begin{array}{l}\text { Work of } \\
\text { Fracture } \\
\left(\mathrm{kJ} \mathrm{m}^{-2}\right)\end{array}$ & $\begin{array}{l}\text { Interfacial } \\
\text { Stress } \\
\text { (MPa) }\end{array}$ & $\begin{array}{c}\text { Fibre } \\
\text { Hardness } \\
(\mathrm{GPa})\end{array}$ & $\begin{array}{c}\text { Degree of } \\
\text { Matrix } \\
\text { Devitrification } \\
\text { (mass\%) }\end{array}$ \\
\hline B : & $\begin{array}{l}\text { As-fabricated } \\
\text { Thermal-shocked }\end{array}$ & $\begin{array}{l}860 \pm 33 \\
746 \pm 44\end{array}$ & $\begin{array}{l}702 \pm 31 \\
484 \pm 21\end{array}$ & $\begin{array}{l}100 \pm 1 \\
95 \pm 1\end{array}$ & $\begin{array}{l}42 \pm 9 \\
39 \pm 4\end{array}$ & $\begin{array}{l}36 \pm 9 \\
13 \pm 2\end{array}$ & $\begin{array}{l}17.4 \pm 0.9 \\
17.0 \pm 1.0\end{array}$ & $\begin{array}{l}15 \pm 1 \\
15 \pm 1\end{array}$ \\
\hline C: & $\begin{array}{l}\text { As-fabricated } \\
\text { Thermal-shocked }\end{array}$ & $\begin{array}{c}1163 \pm 14 \\
773 \pm 22\end{array}$ & $\begin{array}{l}750 \pm 21 \\
454 \pm 11\end{array}$ & $\begin{array}{c}101 \pm 20 \\
93 \pm 3\end{array}$ & $\begin{array}{l}59 \pm 2 \\
34 \pm 5\end{array}$ & $\begin{array}{c}38 \pm 14 \\
16 \pm 3\end{array}$ & $\begin{array}{l}18.1 \pm 0.7 \\
16.0 \pm 0.8\end{array}$ & $\begin{array}{l}12 \pm 1 \\
12 \pm 1\end{array}$ \\
\hline D: & $\begin{array}{c}\text { As-fabricated } \\
\text { Thermal-shocked }\end{array}$ & $\begin{array}{l}1406 \pm 93 \\
821 \pm 86\end{array}$ & $\begin{array}{l}855 \pm 24 \\
492 \pm 32\end{array}$ & $\begin{array}{l}102 \pm 9 \\
95 \pm 3\end{array}$ & $\begin{array}{l}73 \pm 9 \\
39 \pm 5\end{array}$ & $\begin{array}{l}53 \pm 7 \\
17 \pm 2\end{array}$ & $\begin{array}{l}19.0 \pm 0.4 \\
16.2 \pm 1.0\end{array}$ & $\begin{array}{l}9 \pm 2 \\
9 \pm 2\end{array}$ \\
\hline
\end{tabular}

(1) The mechanical properties of as-fabricated samples were taken from the Table 3 of reference [6]. (2) The samples 1-B, 1-C and 1$D$ in Table 3 of Ref. 6 are again designated samples B, C, and D in this work. The thermal shock behaviour of sample $1-A$ which was reinforced with Tyranno fibres was not quoted here, since both the as-fabricated and thermal-shocked composite were failed in a brittle manner. For thermal shock behaviour, four samples were used for the average value quoted in the first three columns. For interfacial stress and fibre hardness, at least 30 fibres were indented for the average values quoted. The error indicates a standard deviation of experimental values.

received samples, as we expected, since $500^{\circ} \mathrm{C}$ is well below the crystallization region in Pyrex.

3.2 Analyses of thermal-mismatch stresses

There are several potential origins which are enable to cause the cracking in Pyrex matrix during thermal-shock treatment: (1) an axial tensile stress in the matrix, (2) debonding of fibre from matrix due to a tensile radial stress acting on interface, (3) thermal-shock stresses as in monolithic ceramics due to rapid cooling, and (4) matrix devitrification.

3.2.1 Thermal-mismatch stress due to the difference of coefficient of thermal expansion between fibre and matrix

While considering the thermal-mismatch stresses developed between fibre and matrix, two different combinations of materials need to be taken into account, i.e., the stress between fibre and crack-free Pyrex glass, and the stress between fibre and devitrified cristobalite if the Pyrex devitrifies on the surface of fibre. In order to analyse the thermal-mismatch stresses of each case, two model systems, i.e., Nicalon/devitrification-free Pyrex glass and Nicalon/cristobalite composites are assumed. For Nicalon fibre/Pyrex glass case, an axial tensile stress and a radial compressive stress occur in the matrix during cooling after consolidation and subsequent quenching, since the coefficient of thermal expansion (CTE) of Pyrex matrix $\left(\alpha_{\mathrm{m}}=3.3 \times 10^{-6} / \mathrm{K}\right)$ is slightly higher than that of fibre $\left(\alpha_{\mathrm{f}}=3.1 \times 10^{-6} / \mathrm{K}\right)$. Assuming that there is no stress relief during cooling after consolidation, the maximum residual stresses can be calculated using Eq. (3) and the values of material parameters taken from the composite studied by Kagawa et al. ${ }^{3)}$ where Pyrex matrix did not devitrify to cristobalite.

The thermal-mismatch stresses between fibre and cristobalite in Nicalon fibre/cristobalite system are calculated by considering the matrix volume change of $3.9 \%$ at $250^{\circ} \mathrm{C}$. That is,

$$
\begin{aligned}
\frac{P}{E_{\mathrm{m}}}= & \frac{1}{2 \lambda_{1}}\left(\frac{V_{\mathrm{m}}}{1-v_{\mathrm{m}}}\right)\left[\int_{20^{\circ} \mathrm{C}}^{250^{\circ} \mathrm{C}}\left(\alpha_{\alpha-\text { cri }}-\alpha_{\mathrm{f}}\right) \mathrm{d} T\right. \\
& \left.+\left(\frac{\Delta V}{3 V}\right)+\int_{250^{\circ} \mathrm{C}}^{520^{\circ} \mathrm{C}}\left(\alpha_{\beta-\text { cri }}-\alpha_{\mathrm{f}}\right) \mathrm{d} T\right] \\
\frac{\sigma_{\mathrm{m}}^{\mathrm{I}}}{E_{\mathrm{m}}}= & \frac{\lambda_{2}}{\lambda_{1}}\left(\frac{E_{\mathrm{f}}}{E_{\mathrm{c}}}\right)\left(\frac{V_{\mathrm{f}}}{1-v_{\mathrm{m}}}\right)\left[\int_{20^{\circ} \mathrm{C}}^{250^{\circ} \mathrm{C}}\left(\alpha_{\alpha-\text { cri }}-\alpha_{\mathrm{f}}\right) \mathrm{d} T\right. \\
& \left.+\left(\frac{\Delta V}{3 V}\right)+\int_{250^{\circ} \mathrm{C}}^{520^{\circ} \mathrm{C}}\left(\alpha_{\beta-\text { cri }}-\alpha_{\mathrm{f}}\right) \mathrm{d} T\right]
\end{aligned}
$$

The calculated values of radial compressive $P$ and axial tenside $\sigma_{\mathrm{m}}^{\mathrm{I}}$ stress developed in the cristobalite locating adjacent to the fibre during cooling are given in Table 2. The axial tensile stress developed in a pure Pyrex matrix is also estimated by the same procedure using $\Delta T=500^{\circ} \mathrm{C}$. The value is $5.5 \mathrm{MPa}$ which is negligibly small in comparison with the first-matrix cracking stress of as-fabricated composite and even the tensile strength of Pyrex glass of $120 \mathrm{MPa}$. Therefore, this stress cannot be a direct cause of matrix cracking. In addition, the compressive stress at the interface of Nicalon/Pyrex is about $2 \mathrm{MPa}$ which is also signficantly lower than the measured interfacial stress shown in Table 1. Thus, if there is no devitrification in the Pyrex matrix, the thermal-mismatch stresses in the matrix and at the interface cannot give rise to matrix cracking and debonding of fibre. However, for extreme case, if the fibre is surrounded by cristobalite, and the surrounding cristobalite phase is debonded from Pyrex matrix, then the maximum axial tensile stress and compressive stress developed along the fibrecristobalite interface can be estsimated using Nicalon/cristobalite model system shown in Table 2. The axial tensile stress developed in the matrix and the tangential tensile stress at the interface are high 
Table 2. Thermal-Mismatch Stresses Due to the Difference of CTE between Fibre and Matrix

\begin{tabular}{l|cc}
\hline Material parameter & Nicalon/pyrex & Nicalon/cristobalite \\
\hline fracture toughness of matrix $\left(K_{C} M, M P a m^{1 / 2}\right)$ & 0.75 & $\sim 2$ \\
Young's modulus of fibre $\left(E_{f}, G P a\right)$ & 155 & 155 \\
Young's modulus of matrix $\left(E_{m}, G P a\right)$ & 65 & 100 \\
Composite modulus $\left(E_{c}, G P a\right)$ & 110 & 127 \\
fibre volume fraction $\left(V_{f}, \%\right)$ & 0.5 & 0.5 \\
fibre radius $(R, \mu m)$ & 8 & 8 \\
CTE of matrix $\left(x 10^{-6 / K}\right)$ & 3.3 & $31.1\left(\mathrm{~T} \leq 250^{\circ} \mathrm{C}\right), 5.65\left(\mathrm{~T} \geq 250^{\circ} \mathrm{C}\right)$ \\
$\mathrm{CTE}$ of Nicalon $\left(\mathrm{x} 10^{-6} / \mathrm{K}\right)$ & 3.1 & 3.1 \\
$\Delta \mathrm{T}\left({ }^{\circ} \mathrm{C}\right)$ & $\sim 500(1)$ & $\sim 500^{(2)}$ \\
Poisson's ratio of matrix $(v)$ & 0.2 & 0.25 \\
& & \\
\hline Calculated values & & 714 \\
$P(M P a)$ from $\mathrm{Eq}(3 \mathrm{a})$ & 2.3 & 1580 \\
$\sigma_{m}^{\prime}(M P a)$ from $\mathrm{Eq}(3 \mathrm{~b})$ & 5.5 & \\
\hline
\end{tabular}

Note that, for the calculation of thermal mismatch stresses, the moduli of composite ( 110 $\mathrm{GPa}$ ) and crack-free pyrex matrix (65 GPa) taken from Kagawa's work [3] are used for asfabricated samples. (1) The strain point of pyrex glass is $520^{\circ} \mathrm{C}$. Thus, from $520^{\circ} \mathrm{C}$ to room temperature of $20^{\circ} \mathrm{C}, \Delta \mathrm{T}$ is equal to $500^{\circ} \mathrm{C}$. (2) The difference in tempreature is assumed as Nicalon/pyrex composite for comparison.

enough to cause matrix cracking and lead to the fragmentation of cristobalite. Thus the cristobalite in contact with the fibre can be fragile and debonded easily from the fibre during cooling in the fabrication process.

SEM micrographs of transverse sections, as shown for example in Fig. 2(A), reveal that in the as-fabricated composites, there are microcracks in and around the cristobalite particles and some partial debonding of fibres from the matrix when the cristobalite particles are located near to the fibre surfaces, even before a stress is applied to the composites. By comparison, the continuity of the bonding is evident along the Pyrex glass-fibre interface.

For the thermal-shocked Nicalon/Pyrex composite, the magnitudes of thermal-mismatch stresses generated due to subsequent quenching from $500^{\circ} \mathrm{C}$ to $20^{\circ} \mathrm{C}$ will be approximately same as the stresses developed during fabrication, because the strain point of Pyrex glass $\left(520^{\circ} \mathrm{C}\right)$ is nearly same as the heating temperature of $500^{\circ} \mathrm{C}$ for subsequent quenching. In this case, the stress generated during heating to $500^{\circ} \mathrm{C}$ does not need to be taken into account, since the axial compressive stress will compensate the tensile stress developed during fabrication. However, if the fibres are bonded by cristobalite matrix, the stress developed during heating should be considered separately. This is because the stress generated at each heat treating step, i.e., fabrication, heating at $500^{\circ} \mathrm{C}$ and quenching to $20^{\circ} \mathrm{C}$, can be dissipated by forming matrix cracks. For Nicalon/cristobalite combination, the maximum possible tensile
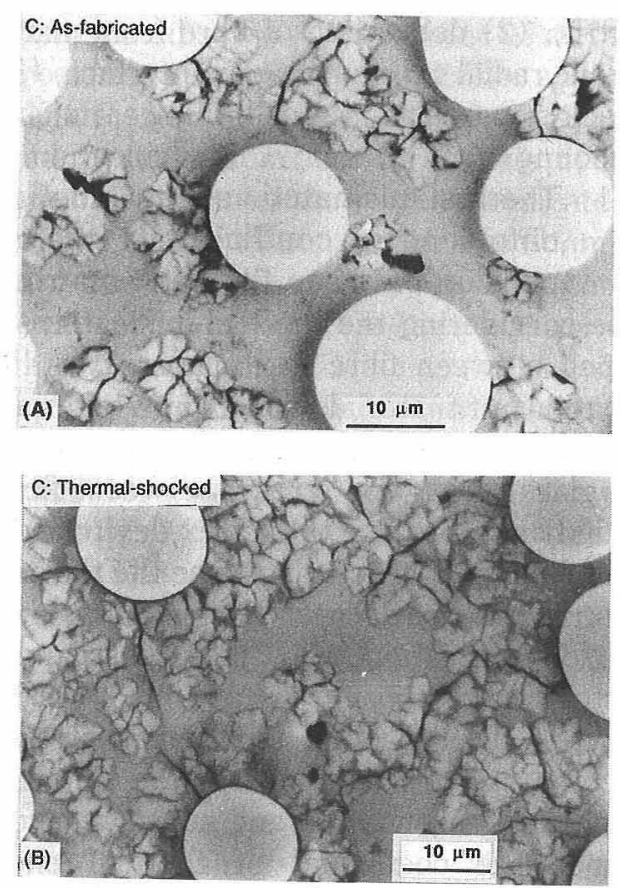

Fig. 2. SEM micrographs taken before flexural test showing (A) microcracking in as-fabricated composite in and around the cristobalite particles and partial debonding of fibre adjacent to cristobalite particles and (B) extended matrix cracking of the thermal-shock treated composite.

stress $P$ and compressive stress $\sigma_{\mathrm{m}}^{\mathrm{I}}$ generated during heating to $500^{\circ} \mathrm{C}$ are about $710 \mathrm{MPa}$ and 1570 $\mathrm{MPa}$, and same magnitudes of opposite stresses will occur during cooling, if the interfacial stress is main- 

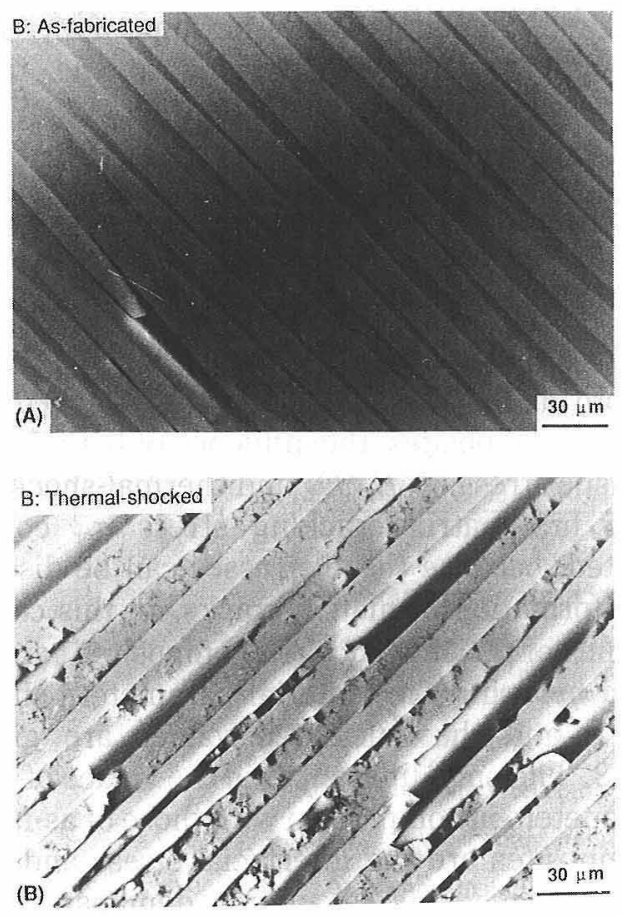

Fig. 3. SEM micrographs of the polished longitudinal surfaces of (A) as-fabricated and (B) thermal-shock treated sample B in Table 1, taken before flexural test, showing more extensive matrix micro-fractures adjacent to fibres and traces of broken fibres of thermal-shock treated composite.

tained as before. However, the actual stresses developed during subsequent heating and quenching are readily expected to be significantly lower than the calculated values, because of weak bonding along interface due to the formation of microcracks.

SEM micrograph of thermal-shocked sample (Fig. 2(B)) shows much extensive crack growth through the cristobalite in the matrix, and severe debonding of fibres when the cristobalite particles are located in the vicinity of fibres. This micrograph demonstrates that the thermal-mismatch stresses developed along the fibre-cristobalite interface during subsequent heating and quenching is at least high enough to extend the pre-existing cracks. The difference in morphology between as-fabricated and thermal-shocked samples can be seen more readily in Fig. 3. SEM micrographs of a polished longitudinal surface of both as-fabricated and thermal-shocked specimens show that in the thermal-shocked sample, there are more traces of broken fibres and micro-fractures in the matrix during grinding and polishing, whereas in as-fabricated samples continuity of the bonding along the matrix-fibre interface is more evident under the same polishing conditions.

\subsubsection{Stress generated by temperature gradi-} ent

The maximum tensile stress developed at the surface of monolithic glass $\sigma_{\max }$ due to thermal gradient while thermal shock treatment can be estimated by, ${ }^{7)}$

$$
\sigma_{\max }=\frac{E_{\alpha}}{1-v} \Delta T
$$

Applying Eq. (4) to the Pyrex glass containing 10 vol\% of cristobalite such as the matrix materials of composite examined in this work could give approximate level of thermal-shock stress developed in the matrix. Assuming that the CTE of composite follows a rule of mixture, ${ }^{8)}$ then $\alpha$ is equal to $6.08 \times$ $10^{-6} / \mathrm{K}$ for $T \leq 250^{\circ} \mathrm{C}$ and $3.35 \times 10^{-6} / \mathrm{K}$ for $T \geq 250^{\circ} \mathrm{C}$, and the strain due to the volume change of $10 \%$ of cristobalite at $250^{\circ} \mathrm{C}$ is about $1.3 \times 10^{-6}$. Using $E_{\mathrm{m}}$ of $45 \mathrm{GPa}, v$ of 0.2 and $\Delta T$ of $480^{\circ} \mathrm{C}$,

$$
\begin{aligned}
\sigma_{\max }= & \frac{E_{\mathrm{m}}}{(1-v)}\left[\int_{20^{\circ} \mathrm{C}}^{250^{\circ} \mathrm{C}} \alpha_{\mathrm{m}} \mathrm{d} T+0.1\left(\frac{\Delta V}{3 V}\right)\right. \\
& \left.+\int_{250^{\circ} \mathrm{C}}^{500^{\circ} \mathrm{C}} \alpha_{\mathrm{m}} \mathrm{d} T\right]
\end{aligned}
$$

The maximum tensile stress developed on the surface of Pyrex glass due to thermal gradient is about $200 \mathrm{MPa}$ which is higher than the strength of Pyrex glass. Thus, the thermal-shock stress could contribute to the onset of matrix cracking.

\subsubsection{Thermal-mismatch stress due to matrix} devitrification

Nicalon/Pyrex composite studied here contains devitrified cristobalite crystals in the matrix, and the differences in CTE between $\alpha$-cristobalite, $\beta$-cristobalite and Pyrex matrix induced severe radial tensile stress within cristobalite particle and in the matrix, and this led to extensive matrix cracking. ${ }^{9)}$ Assuming that the stresses generated during fabrication are all dissipated for the formation of matrix cracks, then the thermal-mismatch stress developed between Pyrex and cristobalite during subsequent quenching from $500^{\circ} \mathrm{C}$ to $20^{\circ} \mathrm{C}$ can be again estimated by the same procedure used for the stresses developed in as-fabricated composites. ${ }^{9)}$

$$
\begin{gathered}
\int_{20^{\circ} \mathrm{C}}^{250^{\circ} \mathrm{C}} \frac{\left(\alpha_{\alpha}-\alpha_{\mathrm{m}}\right)}{\frac{1+v_{\mathrm{m}}}{2 E_{\mathrm{m}}}+\frac{1-2 v_{\mathrm{p}}}{E_{\mathrm{p}}}} \mathrm{d} T+\frac{\frac{\Delta V}{3 V}}{\frac{1+v_{\mathrm{m}}}{2 E_{\mathrm{m}}}+\frac{1-2 v_{\mathrm{p}}}{E_{\mathrm{p}}}} \\
+\int_{250^{\circ} \mathrm{C}}^{500^{\circ} \mathrm{C}} \frac{\left(\alpha_{\beta}-\alpha_{\mathrm{m}}\right)}{\frac{1+v_{\mathrm{m}}}{2 E_{\mathrm{m}}}+\frac{1-2 v_{\mathrm{p}}}{E_{\mathrm{p}}}} \mathrm{d} T
\end{gathered}
$$

Using the material parameters of $E_{\mathrm{m}}$ of $45 \mathrm{GPa}$ and $3.9 \%$ volume change at $\beta \rightarrow \alpha$ transition temperature, we can obtain $P$ of $1090 \mathrm{MPa}$. From this value, the radial tensile stress of $1090 \mathrm{MPa}$ and the tangential compressive stress of $545 \mathrm{MPa}$ in the matrix can be obtained. The tensile stress within cristobalite particles will be $1090 \mathrm{MPa}$. While heating from $20^{\circ} \mathrm{C}$ to $500^{\circ} \mathrm{C}$, the same magnitudes of opposite stresses occur. These calculated thermal-mismatch stresses, however, could only indicate the maximum stresses developed under the conditions assumed before. Thus, the true thermal-mismatch stresses could be 
much lower than the calculated values.

However, the SEM micrographs of transverse section of as-fabricated sample (Fig. 2(A)) clearly show the effect of thermal-mismatch stress on the matrix cracking. For thermal-shocked composite, the pre-existing cracks in the cristobalite are further extended to the Pyrex matrix region, as shown in Fig. 2(B), and Fig. 3(B) in comparison with Fig. $3(\mathrm{~A})$. Thus, the thermal-mismatch stresses developed between cristobalite and Pyrex matrix either during heating up to $500^{\circ} \mathrm{C}$ or quenching, or combination of these two, can give rise to further extension of pre-existing cracks and new cracks in the matrix.

\subsection{Modulus of thermal-shocked composites}

The elastic modulus of thermal-shocked composite is about $95 \mathrm{GPa}$ which is lower than an average value $(\sim 100 \mathrm{GPa})$ of as-fabricated samples. The composite modulus $E_{\mathrm{c}}$ reported by Kagawa's work ${ }^{3)}$ indicate that the $E_{\mathrm{c}}$ value changes from $\sim 110 \mathrm{GPa}$ to $95 \mathrm{GPa}$, depending on severity of matrix cracking, i.e., $\sim 110 \mathrm{GPa}$ for the crack-free composites and $\sim$ $95 \mathrm{GPa}$ for the thermal-shocked samples $(\Delta T$ $=800^{\circ} \mathrm{C}$ ) containing extensive matrix cracking. From the elastic moduli of Pyrex matrix $(65 \mathrm{GPa})$ and composite $(110 \mathrm{GPa})$ for the as-fabricated Nicalon/Pyrex composite, ${ }^{3)}$ the fibre modulus $\left(E_{\mathrm{f}}\right)$ of $155 \mathrm{GPa}$ can be obtained from a rule of mixture. Applying an $E_{\mathrm{f}}$ of $155 \mathrm{GPa}$ to the thermal-shocked specimens $\left(E_{\mathrm{c}}=95 \mathrm{GPa}\right)$ studied here gives the matrix modulus of $35 \mathrm{GPa}$ which is about $22 \%$ lower than that $(45 \mathrm{GPa})$ of as-fabricated samples representing further matrix cracking during thermal-shock treatment.

Based on the calculation of thermal stresses and SEM pictures, the decrease of matrix modulus in thermal-shocked composite can be attributed to the cracks originating from the matrix devitrification. The thermal-mismatch stresses between fibre and cristobalite can give rise to severe debonding along fibre-matrix interface and extensive matrix cracking in the cristobalite and in the Pyrex glass matrix. The stresses developed between cristobalite and Pyrex glass extend the pre-existing cracks in cristobalite to the surrounding Pyrex region, and also generate new cracks. This results in low modulus and low interfacial stress of the thermal-shocked composites relative to the as-fabricated samples. The tensile stress generated by thermal-shock can contribute to matrix cracking, but this could be the second order effect in comparison with the thermal-mismatch stresses.

3.4 Proportional limit of thermal-shocked composite

The proportional limit $(\sim 460 \mathrm{MPa})$ of thermalshocked composite is significantly lower than those $(700-850 \mathrm{MPa})$ of as-fabricated samples. The influence of a residual axial stress on the failure strain of matrix containing a steady-state crack for which the stress concentration at the tip of the crack is independent on the crack size can be estimated from Eq. (1). 1) Using the relationships of $\sigma_{\mathrm{cr}}=E_{\mathrm{c}} \varepsilon_{\mathrm{mu}}$, $2 \gamma_{\mathrm{m}}=K_{\mathrm{c}}^{\mathrm{M}^{2}}\left(1-v^{2}\right) / E_{\mathrm{m}}$ where $K_{\mathrm{c}}^{\mathrm{M}}$ is the fracture toughness of matrix, and $\eta=E_{\mathrm{f}} V_{\mathrm{f}} / E_{\mathrm{m}} V_{\mathrm{m}}$, Eq. (1) can be expressed again by,

$$
\begin{aligned}
\sigma_{\mathrm{cr}}= & 6^{1 / 3}\left[\frac{\left(1-v^{2}\right)\left(K_{\mathrm{c}}^{\mathrm{m}}\right)^{2} \tau E_{\mathrm{f}} V_{\mathrm{f}}^{2} V_{\mathrm{m}}(1+\eta)^{2}}{E_{\mathrm{m}} r}\right]^{1 / 3} . \\
& -\frac{E_{\mathrm{c}}}{E_{\mathrm{m}}} \sigma_{\mathrm{m}}^{\mathrm{I}}
\end{aligned}
$$

For both as-fabricated and thermal-shocked Nicalon/Pyrex composites, the influence of both the residual tensile stress $\sigma_{\mathrm{m}}^{\mathrm{I}} E_{\mathrm{c}} / E_{\mathrm{m}}$ and thermal-shock stress on the first-matrix cracking stress $\sigma_{\mathrm{cr}}$ could be neglected, because these stresses can be dissipated by the formation of matrix cracks. In this case, the $\sigma_{\mathrm{cr}}$ values of thermal-shocked composites can be calculated by using the material parameters shown in Table 1 , and the calculated values are given in Table 3. The only differences in the values of material parameters in comparison with those of as-fabricated composites are the interfacial stress and matrix modulus. Thus, this calculation demonstrates how the variation of $\tau$ and $E_{\mathrm{m}}$ before and after thermalshock treatment can affect the first-matrix cracking stress and the steady-state crack size.

For the thermal-shocked composites, the stresses originating from devitrified particles extended the pre-existing matrix cracks and also reduced the apparent interfacial stress by debonding fibres from matrix. These extended cracks can be joined together around the fibres at the relatively lower applied stress than in the as-fabricated composite, because the thermal-shocked composite has larger inherent matrix cracks and a lower matrix-fibre interfacial shear stress. A typical cracking pattern of thermal-shocked sample after flexure test is shown in Fig. 4 which demonstrates the joining of matrix cracks through debonded interface region at certain level of applied stress. Thus, the matrix cracking stress of thermal-shocked samples could be predicted by the steady-state crack behaviour. Whereas, in as-fabricated composits, the extension of initially short matrix crack are hindered by relatively strong interfacial stress while applying external stress, so the crack may not grow to a steady-state crack size. $\left.{ }^{6}\right)$ In fact, the proportional limits of thermal-shocked composites agree well with the values predicted by steady-state crack behaviour. Thus, the lower proportional limit of thermal-shocked composite in comparison with as-fabricated samples can be attributed to lower apparent interfacial stresses and larger initial crack size.

\subsection{Ultimate strength of thermal-shocked com- posite}

The ultimate flexural strengths of thermal-shocked composites are a roughly constant value of $\sim 760$ $\mathrm{MPa}$ which is significantly lower than the values (850-1400 MPa) of as-fabricated composite. The values of fibre hardness of thermal-shocked samples 
Table 3. Comparison of the Measured Proportional Limits with the Calculated First-Matrix Cracking Stresses

\begin{tabular}{|l|cc|c|}
\hline & \multicolumn{2}{|c|}{ Experimental result } & Calculated $\sigma_{c r}$ value $(1)$ \\
\hline Specimens & $\begin{array}{l}\text { Proportional } \\
\text { limit }(\mathrm{MPa})\end{array}$ & $\begin{array}{c}\text { Interfacial } \\
\text { stress }(\mathrm{MPa})\end{array}$ & $\mathrm{Eq}(5)$ \\
\hline B: As-fabricated & $702 \pm 31$ & $36 \pm 9$ & 498 \\
Thermal-shocked & $484 \pm 21$ & $13 \pm 9$ & 441 \\
\hline & & & \\
C: As-fabricated & $750 \pm 21$ & $38 \pm 14$ & 507 \\
Thermal-shocked & $454 \pm 11$ & $16 \pm 3$ & 472 \\
\hline & & & \\
D: As-fabricated & $855 \pm 24$ & $53 \pm 7$ & 567 \\
Thermal-shocked & $492 \pm 32$ & $17 \pm 2$ & 482 \\
\hline
\end{tabular}

(1) The value of parameters used for calculation are: $E_{f}$ is $155 \mathrm{GPa}, E_{m}$ of as-fabricated composite is $45 \mathrm{GPa}$ taken from average $E_{C}$ of $100 \mathrm{GPa}, E_{m}$ of thermal-shocked composite is $35 \mathrm{GPa}$ obtained from average $E_{C}$ of 95 $\mathrm{GPa}, \tau$ is the average value of interfacial stress shown in $2 \mathrm{nd}$ column, $V_{f}$ is $0.5, R$ is $8 \mu \mathrm{m}$ and $v$ is 0.2 .

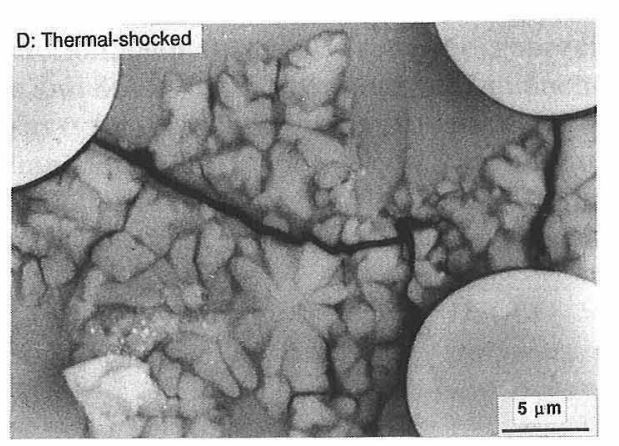

Fig. 4. SEM micrograph of the thermal-shock treated sample D in Table 1 after flexural test showing matrix crack junction.

are generally lower than those of as-fabricated composites. This tendency confirms that the variation of fibre hardness can be correlated with a change in fibre strength, and thus ultimate strength of composite.

SEM micrograph of thermal-shocked composites show that the fractured areas in the matrix adjacent to fibre are associated with microcracks in the fibre (Fig. 5). The devitrified matrix becomes more fragile when subjected to thermal-shock treatment, so these regions would be easily removed by a grinding and polishing procedure. Thus, the matrix regions in the groove near by fibre can be reasonably assumed to be the places previously occupied by devitrified cristobalite. Therefore, the fibre microcracks in the vicinity of matrix regions in the groove can be attributed to the stress originaing from presence of cristobalite. While the cristobalite adjacent to a fibre is expanding ( $\alpha \rightarrow \beta$ transition) during heat treatment beyond the transition temperature, there are axial tensile and radial compressive

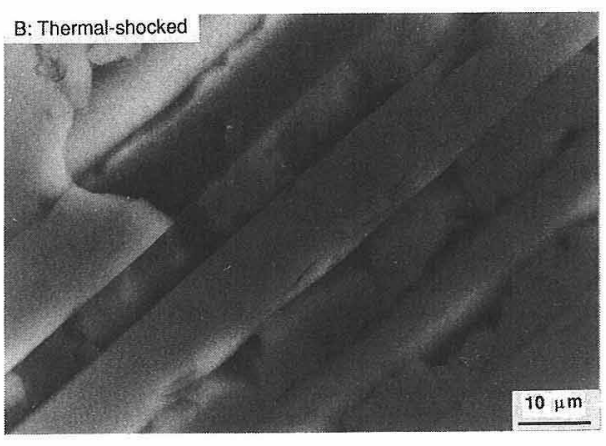

Fig. 5. SEM micrograph taken from the thermal-shock treated composite before flexural test showing a fibre with micro-fractures in the vicinity of the matrix micro-fracture.

stresses in the fibre. When the cristobalite is contracting ( $\beta \rightarrow \alpha$ transition) during cooling, it will force the fibre to be in axial compression and radial tension. These cyclic stresses could cause the microfracture in the fibre and the debonding of fibre from matrix, as shown Figs. 5 and 2(B). The reduced apparent interfacial shear stress of thermal-shocked samples can also be contributed to the lower values of ultimate strength compared with the ultimate strengths of as-fabricated composites.

\section{Conclusions}

The mechanical properties of thermal-shocked composite are all significantly lower than those of asfabricated composites. The lower modulus ( $\sim 95$ $\mathrm{GPa}$ ) of thermal-shocked sample in comparison with as-fabricated composites was analysed in the light of matrix cracking. The thermal stresses generated along both the fibre-cristobalite and Pyrex-cristobalite interfaces are high enough to cause fibre debond- 
ing and extensive cracks in and around cristobalite. The micrographs confirmed the cracking patterns predicted by the stress analyses. Thus, the reductions of modulus and interfacial stress of thermalshocked composites resulted from the stress originating from presence of cristobalite. SEM micrographs taken after flexural test showed the joining of extended matrix cracks through fibre-matrix interface. The lower proportional limit of thermal-shocked samples compared with as-fabricated composites resulted from low interfacial stress and larger pre-existing cracks. Thus the proportional limit varies depending on the pre-existing crack size and interfacial stress as predicted by the fracture mechanics approach. The low interfacial stress combined with fibre damage represented by low fibre hardness led to lower ultimate strength. This confirmed that the variation of fibre hardness can be correlated with the level of ultimate strength.

\section{References}

1) D. B. Marshall and A. G. Evans, J. Am. Ceram. Soc., 68, 22531 (1985).

2) D. M. Dawson, R. F. Preston and A. Purser, Proc. Br. Ceram., 39 (1987) pp. 221-28.

3) Y. Kagawa, N. Kurosawa, T. Kishi, Y. Tanaka, Y. Imai and H. Ichikawa, Ceram. Eng. Sci. Proc., 10, 1327-36 (1989).

4) M. C. Long, R. E. Moore, D. E. Day, J. G. Wesling and R. Burns, Ceram. Eng. Sci. Proc., 10, 1231-43 (1989).

5) B. Budiansky, J. W. Hutchison and A. G. Evans, J. Mech. Phys. Solids, 34, 167-89 (1986).

6) D.-W. Shin and K. M. Knowles, J. Ceram. Soc. Japan, 103, 409-17 (1995).

7) S. S. Manson, "Thermal Stress and Low-Cycle Fatigue", MacGraw-Hill (1966) p. 404.

8) J. H. Jean and T. K. Gupta, J. Mater. Res., 7, 3103-11 (1992).

9) D.-W. Shin and K. M. Knowles, J. Ceram. Soc. Japan, 103, 319-24 (1995). 